\title{
Transaminases for the synthesis of enantiopure beta-amino acids
}

\author{
Jens Rudat, Birgit R Brucher and Christoph Syldatk
}

\begin{abstract}
Optically pure $\beta$-amino acids constitute interesting building blocks for peptidomimetics and a great variety of pharmaceutically important compounds. Their efficient synthesis still poses a major challenge. Transaminases (also known as aminotransferases) possess a great potential for the synthesis of optically pure $\beta$-amino acids. These pyridoxal 5'-dependent enzymes catalyze the transfer of an amino group from a donor substrate to an acceptor, thus enabling the synthesis of a wide variety of chiral amines and amino acids. Transaminases can be applied either for the kinetic resolution of racemic compounds or the asymmetric synthesis starting from a prochiral substrate. This review gives an overview over microbial transaminases with activity towards $\beta$-amino acids and their substrate spectra. It also outlines current strategies for the screening of new biocatalysts. Particular emphasis is placed on activity assays which are applicable to high-throughput screening.
\end{abstract}

Keywords: transaminase, beta-amino acid, high-throughput screening, biocatalysis

\section{Introduction}

Since the discovery of transamination in biological systems (Braunstein and Kritzmann 1937,Moyle Needham 1930,) the significance of transaminases (TAs) for amino acid metabolism has been the subject of intensive research. Over the last 15 years, TAs have gained increasing attention in organic synthesis for the biocatalytic production of a wide variety of chiral amines and $\alpha$-amino acids. This has been discussed in detail in a series of excellent reviews (Höhne and Bornscheuer 2009,; Koszelewski et al. 2010,; Taylor et al. 1998,; Ward and Wohlgemuth 2010). Advantages in the use of TAs lie in mostly low-cost substrates, no necessity for external cofactor recycling and the enzymes' high enantioselectivity and reaction rate. For the synthesis of enantiopure $\beta$-amino acids only a limited number of TAs are available. Therefore efficient screening techniques for TAs with high activities as well as broader substrate specificity and different enantioselectivities are crucial for the successful application of transaminases for the synthesis of $\beta$-amino acids. Of particular interest

\footnotetext{
* Correspondence: jens.rudat@kit.edu Institute of Process Engineering in Life Sciences, Section II: Technical Biology, Karlsruhe Institute of Technology (KIT), Engler-Bunte-Ring 1, 76131 Karlsruhe, Germany
}

are methods that can be used at small scale compatible with microtiter plates.

Enantiopure $\beta$-amino acids represent highly valuable building blocks for peptidomimetics and the synthesis of bioactive compounds. In order to distinguish positional isomers of $\beta$-amino acids, the terms $\beta^{2}$-, $\beta^{3}$ - and $\beta^{2,3}$ amino acids have been introduced by Seebach and coworkers (Hintermann and Seebach 1997; Seebach et al. 1997$,$) . With the exception of \beta$-alanine and $\beta$-aminoisobutyric acid which constitute key intermediates in several metabolic pathways, $\beta$-amino acids are not as abundant in nature as $\alpha$-amino acids. However, they occur as essential parts in a variety of biologically active compounds. Notable representatives are the antineoplastic agent paclitaxel (= Taxol ${ }^{\mathrm{TM}}$, Bristol-Myers Squibb) (Wani et al. 1971,) and the chromophore of C-1027 (= lidamycin), a radiomimetic antitumor agent ( $\mathrm{Hu}$ et al. 1988) (Figure 1a). $\beta$-Amino acids have drawn much attention as building blocks for synthetic peptides. They can form oligomers analogous to $\alpha$-peptides with one additional carbon atom in the oligomer backbone (Figure $1 \mathrm{~b})$. These $\beta$-amino acid oligomers (= $\beta$-peptides) can form highly ordered secondary structures analogous to $\alpha$-peptides (Iverson 1997,; Koert 1997; Seebach et al. 1996,; Seebach and Matthews 1997). $\beta$-Peptides are not recognized by most peptidases and thus not cleaved 

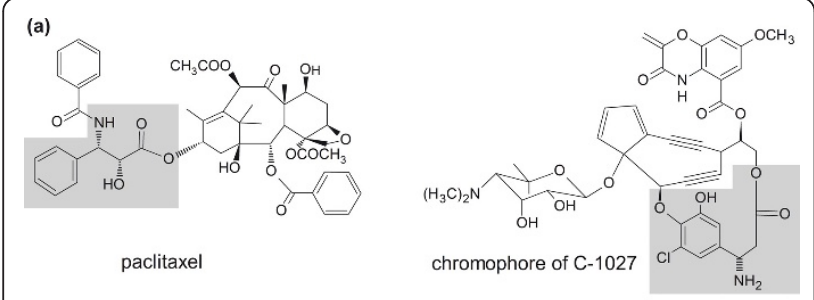

(b)

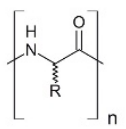

$\alpha$-peptide

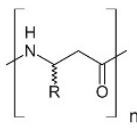

$\beta^{3}$-peptide

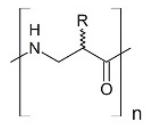

$\beta^{2}$-peptide
Figure 1 (a) Examples of pharmaceutically important natural products containing a $\beta$-amino acid moiety: paclitaxel from the yew tree Taxus brevifolia and the chromophore of the chromoprotein C-1027 from the Actinobacteria Streptomyces griseus. The $\beta$-amino acid moieties are highlighted in grey. (b) Comparison of the backbones of $\alpha-, \beta^{3}$ - and $\beta^{2}$-peptides.

leading to a much higher in vivo stability compared to $\alpha$-peptides (Frackenpohl et al. 2001,; Gopi et al. 2003,; Hintermann and Seebach 1997,; Hook et al. 2004,). It has also been observed that the substitution of only a few $\alpha$-amino acids in a peptide by the corresponding $\beta$ amino acid lowers the proteolytic susceptibility (Horne et al. 2009,; Steer et al. 2002,). Apparently, the $\beta$-residues in mixed $\alpha / \beta$-peptides tend to protect nearby amides from proteolytic cleavage. Interestingly, such mixed $\alpha / \beta$-peptides often retain their biological activity (Aguilar et al. 2007,; Horne et al. 2009,; Montero et al. 2009;; Nurbo et al. 2008,Seebach and Gardiner 2008

A plethora of chemical approaches have been established to produce chiral $\beta$-amino acids including (1) the resolution of racemic $\beta$-amino acids, (2) the use of naturally occurring chiral $\alpha$-amino acids, and (3) asymmetric synthesis (Liu and Sibi 2002,). As resolutions of racemic mixtures are complex and time-consuming procedures, the chiral pool of natural $\alpha$-amino acids is limited and catalysts or chiral auxiliaries cause high costs, all of these strategies have their limitations when applied on an industrial scale (Weiner et al. 2010).

Several enzymes have successfully been tested to produce enantiopure $\beta$-amino acids from different starting compounds (for an overview see Liljeblad and Kanerva 2006). Most strategies resemble kinetic resolutions of $N$ acylated or esterified $\beta$-amino acids by hydrolytic enzymes, e.g. lipases (Tasnádi et al. 2008,). Although industrially applied for certain products, this strategy is limited to a maximum yield of $50 \%$, and so is the recently tested $\beta$-amino acid synthesis via Bayer-Villiger monooxygenases (Rehdorf et al. 2010). As the latter enzymes are cofactor (NADPH) dependent, these processes rely on cofactor recycling which is achieved by whole cell biotransformations, assumingly leading to side products as well as transport limitations depending on the substrate which moreover needs to be $N$ protected.

Two other novel approaches seem to be more promising as they - at least theoretically - can lead to a $100 \%$ conversion of the substrates used and thus overcome the inherent drawback of kinetic resolutions with the above described enzymes:

(1) Various aminomutases have been used for the conversion of aliphatic and aromatic $\alpha$-amino acids to the corresponding $\beta$-isomers (for an overview see $\mathrm{Wu}$ et al. 2010a). Coupling the catalysis of a promiscuous alanine racemase with that of phenylalanine aminomutase (PAM) increased the production of enantiopure (R)- $\beta$ arylalanines from the corresponding racemic $\alpha$-isomers (Cox et al. 2009). Using PAM in tandem with a phenylalanine ammonia lyase (PAL), various aromatic (S)- $\beta$ amino acids can be obtained (Wu et al. 2010b,). These latter studies deal with one potential pitfall of utilizing these enzymes which lies in the reaction's equilibrium and the thus limited final yields of the desired products. Another limitation for application in industry is the usually low activity, leading to quite slow conversions. Moreover, many otherwise promising aminomutases require multiple expensive cofactors and strictly anaerobic conditions Wu et al. 2010a.

(2) A modification of the well established hydantoinase process is investigated for the production of enantiopure $\beta$-amino acids from dihydropyrimidine derivatives (Engel et al. 2011). The stereoselective hydrolysis of racemic phenyldihydrouracil to D- and L-N-carbamoyl- $\beta$-phenylalanine was shown which can be further hydrolyzed to the corresponding $\beta$-amino acid. However, at the moment this process lacks a suitable racemase (or alternatively an efficient chemical racemization) to gain a $100 \%$ yield.

In conclusion, even though several chemical and enzymatic routes (and chemo-enzymatic tandems) are applied and under intense investigation, there still is no gold standard for the preparation of enantiopure $\beta$ amino acids.

TAs can be applied either in the kinetic resolution of racemic $\beta$-amino acids (Figure $2 \mathrm{a}$ ) or in asymmetric synthesis starting from the corresponding prochiral $\beta$ keto-substrate (Figure 2b). By asymmetric synthesis, a theoretical yield of $100 \%$ is possible. However, unlike $\alpha$ keto acids, $\beta$-keto acids decarboxylate relatively easily under mild conditions in a mechanism involving a cyclic transition state (Bach and Canepa 1996). Therefore insitu synthesis would be necessary. This can be achieved by enzymatic hydrolysis of the corresponding $\beta$-keto ester, as was already shown using a commercially available lipase from Candida rugosa (Kim et al. 2007,) and a hog liver esterase (Banerjee et al. 2005). 


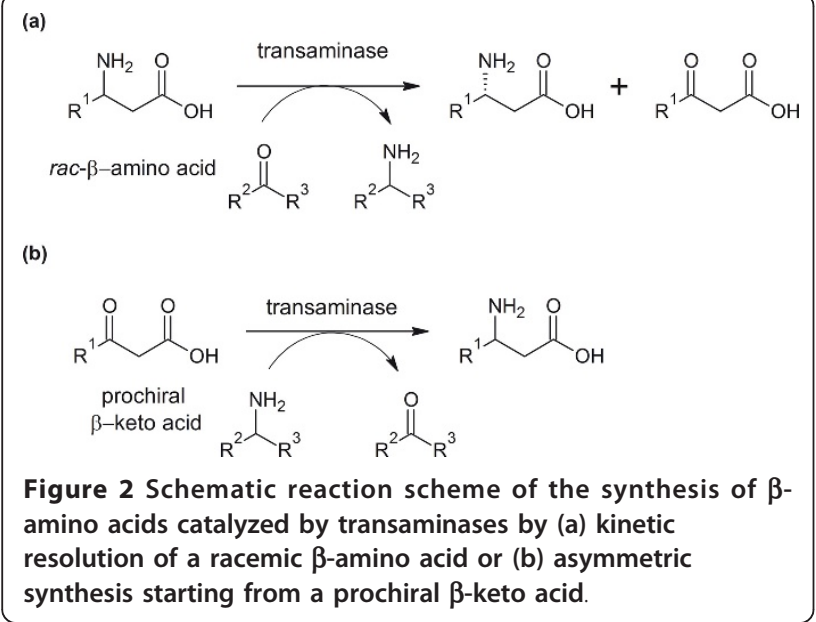

\section{Reaction mechanism}

Formally, the reaction catalyzed by TAs can be considered a redox reaction with the oxidative deamination of the donor in conjunction with the reductive amination of the acceptor. The reaction is divided into two halfreactions obeying a ping-pong bi-bi mechanism. TAs belong to the large and diverse group of pyridoxal phosphate (PLP)-dependent enzymes and are ubiquitous in living organisms playing an important role in amino acid metabolism (Christen and Metzler 1985, Cooper and Meister 1989; Taylor et al. 1998,). So far only the reaction mechanism of aspartate transaminase (EC 2.6.1.1) has been studied extensively, which is assumed to be typical of pyridoxal-5'-phosphate dependent transaminases (Frey and Hegeman 2007,Shin and Kim 2002,). The reaction starts with the deamination of aspartate to $\alpha$-ketoglutarate. In the resting enzyme PLP is covalently bound to the $\varepsilon$-amino group of a lysine (Lys258) in the active site of the apoenzyme forming the internal aldimine. Upon contact with the substrate, the bond between cofactor and apoenzyme dissolves, and PLP forms a Schiff base with the substrate (= the external aldimine). The free $\varepsilon$-amino group of Lys 258 then acts as a catalyst for the 1,3-prototropic shift to form the ketimine. The ketimine is hydrolyzed to yield the keto acid and PMP. The following second half reaction consists of the formation of glutamate from $\alpha$-ketoglutarate. Following the same reaction steps in reverse, the internal aldimine is regenerated (Eliot and Kirsch 2004, Hayashi et al. 2003).

\section{Classification of transaminases}

Over the last decades several classification systems for TAs were established based either on function or evolutionary relationships. PLP-dependent enzymes are divided into seven major structural groups (fold types), which presumably represent five evolutionary lineages
(Grishin et al. 1995,Schneider et al. 2000,). Nonetheless, PLP-dependent enzymes encompass more than 140 distinct catalytic functions, thus representing a striking example of divergent evolution. This makes a correlation between sequence and function especially demanding. Recently, an extensive database has been built, which compiles information on PLP-dependent enzymes (Percudani and Peracchi 2009,). Among the seven fold types of PLP-dependent enzymes, TAs occur in the fold types I and IV. Multiple sequence alignments by the Protein Family Database (Pfam) (Finn et al. 2010) led to the distinction of six subfamilies (classes) of TAs within the superfamily of PLP-dependent enzymes which are designated by Roman numerals (Table 1 ). The classes I and II, III and V all belong to the same folding type. Representatives of class I and II are aspartate TAs and aromatic TAs, of class III $\omega$-TAs and of class V phosphoserine TAs. D-alanine TAs and branched chain amino acid TAs are set apart, pertaining to a different folding type, and unsurprisingly to a different subfamily. According to EC nomenclature, TAs are classified as transferases (EC 2) and not oxidoreductases, as the distinctive feature of the reaction is the transfer of the amino group. Names are generated according to the scheme donor:acceptor transaminase, e.g. asparagine: oxo-acid transaminase (EC 2.6.1.14). As of January 2012 81 different subgroups are listed under EC 2.6.1 (excluding deleted EC numbers). A broader classification based on the reaction catalyzed was introduced in the $1980 \mathrm{~s}$. TAs are divided into two groups: $\alpha$-TAs which catalyze transamination of amino groups at the $\alpha$-carbon and $\omega$ TAs that act on the distal amino group of the substrate (Burnett et al. 1979, Yonaha et al. 1983,). According to this classification, all TAs acting on $\beta$-amino acids are considered as $\omega$-TAs. It was observed that some $\omega$-TAs are able to catalyze the transamination of primary amine compounds not bearing carboxyl groups (Yonaha et al. 1977$,$) . This led to an increasing interest in \omega$-TAs in recent years for the asymmetric synthesis of chiral amines of high enantiopurity (Hwang et al. 2005,Koszelewski et al. 2010,Shin and Kim 1999). Some biotechnologically important $\omega$-TAs, such as the well characterized TA from Vibrio fluvialis JS17, have been denominated 'amine transaminases' accounting for their high activity towards amines while showing only low or no activity towards 'classical' $\omega$-TA substrates, like $\beta$ alanine (Shin et al. 2003).

\section{Substrate spectra of TAs showing activity towards $\beta$ - amino acids \\ Transaminases from wild-type microorganisms}

Table 2 gives an overview over selected $\omega$-TAs which show activity towards $\beta$-amino acids. $\beta$-Alanine:pyruvate TAs (E.C.2.6.1.18) and $\beta$-aminoisobutyrate: $\alpha$ - 
Table 1 Protein subfamilies of TAs according to Pfam; abbreviations: $\alpha-K G=\alpha$-ketoglutaric acid, PYR $=$ pyruvate.

\begin{tabular}{|c|c|c|c|c|c|c|c|}
\hline $\begin{array}{c}\text { protein sub- } \\
\text { families }\end{array}$ & $\begin{array}{c}\text { Pfam } \\
\text { ID }\end{array}$ & $\begin{array}{c}\text { folding } \\
\text { type }\end{array}$ & members & amino donor & $\begin{array}{c}\text { amino } \\
\text { acceptor }\end{array}$ & EC & $\begin{array}{l}\alpha-/ \omega- \\
\text { TAs }\end{array}$ \\
\hline \multirow[t]{2}{*}{ I and || } & 00155 & I & aspartate TA & L-aspartate & $\alpha-K G$ & 2.6 .1 .1 & $\alpha$ \\
\hline & & । & aromatic TA & L-phenylalanine & $\alpha-K G$ & 2.6.1.57 & $\alpha$ \\
\hline \multirow[t]{5}{*}{ III } & 00202 & I & acetylornithine TA & acetylornithine & $\alpha-K G$ & 2.6.1.11 & $\omega$ \\
\hline & & I & ornithine TA & ornithine & $\alpha-K G$ & 2.6.1.13 & $\omega$ \\
\hline & & । & $\beta$-alanine:pyruvate TA & $\beta$-alanine & PYR & 2.6.1.18 & $\omega$ \\
\hline & & । & $\begin{array}{c}\beta \text {-TA from Mesorhizobium sp. } \\
\text { LUK }\end{array}$ & $\beta$-phenylalanine & $\alpha-K G$ or PYR & n.c. ${ }^{1)}$ & $\omega$ \\
\hline & & । & 4-aminobutyrate TA & 4-aminobutyrate & $\alpha-K G$ & 2.6.1.19 & $\omega$ \\
\hline \multirow[t]{2}{*}{ IV } & 01063 & IV & D-alanine TA & D-alanine & $\alpha-K G$ & 2.6.1.21 & $\alpha$ \\
\hline & & IV & branched-chain amino-acid TA & leucine & $\alpha-K G$ & 2.6.1.42 & $\alpha$ \\
\hline v & 00266 & । & phosphoserine TA & phosphoserine & $\alpha-K G$ & 2.6.1.52 & A \\
\hline $\mathrm{Vl}$ & 01041 & I & ArnB & $\begin{array}{l}\text { UDP-4-amino-4-deoxy-beta-L- } \\
\text { arabinose }\end{array}$ & $\alpha-K G$ & 2.6.1.87 & $\alpha$ \\
\hline
\end{tabular}

1) n.c. = not classified

ketoglutarate TAs (E.C.2.6.1.22) are abundant in living cells, because they are involved in several important metabolic pathways such as pyrimidine degradation. Thus, numerous $\omega$-TAs acting on aliphatic $\beta$-amino acids are known. Table 2 only includes a few examples which are of biotechnological relevance. In contrast, only few TAs with aromatic target compounds are known. TAs with high activity towards short-chain

Table 2 Comparison of the substrate spectra of selected $\omega$-TAs.

\begin{tabular}{|c|c|c|c|c|c|}
\hline \multirow[t]{3}{*}{ organism } & \multicolumn{5}{|c|}{ amino donors } \\
\hline & \multicolumn{3}{|c|}{ aliphatic $\beta$-amino acid } & \multirow{2}{*}{$\begin{array}{c}\text { aromatic } \beta \text {-amino acid } \\
\beta \text {-PHE }\end{array}$} & \multirow{2}{*}{$\begin{array}{c}\text { aromatic amine } \\
\alpha-\mathrm{MBA}\end{array}$} \\
\hline & $\beta-A L A$ & $\beta-A B A$ & $\gamma$-ABA & & \\
\hline $\begin{array}{c}\text { Pseudomonas sp. F-126 } \\
\text { (Yonaha et al. 1976; Yonaha et al. 1977) }\end{array}$ & ++ & ++ & + & & \\
\hline $\begin{array}{l}\text { Moraxella lacunata WZ34 } \\
\quad \text { (Chen et al. 2008) }\end{array}$ & ++ & & & & \\
\hline $\begin{array}{c}\text { Alcaligenes denitrificans Y2k-2 } \\
\text { (Yun et al. 2004) }\end{array}$ & + & ++ & & - & + \\
\hline $\begin{array}{l}\text { Caulobacter crescentus } \\
\text { (Hwang and Kim 2004) }\end{array}$ & ++ & ++ & & + & ++ \\
\hline $\begin{array}{l}\text { V. fluvialis JS17 } \\
\text { (Shin and Kim 2002) }\end{array}$ & - & + & - & - & ++ \\
\hline $\begin{array}{l}\text { Chromobacterium violaceum } \\
\text { (Kaulmann et al. 2007) }\end{array}$ & - & + & + & - & ++ \\
\hline $\begin{array}{l}\text { Arthrobacer sp. KNK168 } \\
\text { (Iwasaki et al. 2006) }\end{array}$ & - & & - & & ++ \\
\hline $\begin{array}{l}\text { Alcaligenes eutrophus } \\
\text { (Banerjee et al. 2005) }\end{array}$ & - & & & ++ & \\
\hline $\begin{array}{l}\text { Mesorhizobium LUK sp. } \\
\quad \text { (Kim et al. 2007) }\end{array}$ & & ++ & & ++ & + \\
\hline $\begin{array}{l}\text { Mesorhizobium loti MAFF303099 } \\
\text { (Kwon et al. 2010) }\end{array}$ & & & & ++ & \\
\hline $\begin{array}{l}\text { Variovorax paradoxus } \\
\text { (Banerjee et al. 2005) }\end{array}$ & & & & ++ & \\
\hline $\begin{array}{l}\text { Variovorax sp. JH2 } \\
\text { (Mano et al. 2006) }\end{array}$ & & & & ++ & \\
\hline $\begin{array}{l}\text { Variovorax sp. BC114 } \\
\text { (Brucher et al. 2010) }\end{array}$ & & & & ++ & \\
\hline $\begin{array}{l}\text { Burkholderia sp. BS115 } \\
\text { (Brucher et al. 2010) }\end{array}$ & & & & ++ & \\
\hline
\end{tabular}

$(++)$ high activity, (+) low activity, (-) no activity, () no data available; abbreviations: $\beta$-ALA $=\beta$-alanine, $\beta$-ABA $=\beta$-amino-n-butyric acid, $\gamma$-ABA $=\gamma$-aminobutyric acid, $\beta$-PHE $=\beta$-phenylalanine, $\alpha-\mathrm{MBA}=\alpha$-methylbenzylamine. 
aliphatic $\beta$-amino acids such as $\beta$-alanine and $\beta$-amino$\mathrm{n}$-butyric acid often possess activity towards aromatic amines like $\alpha$-methylbenzylamine, yet no or only low activity towards aromatic $\beta$-amino acids. The well-characterized $\omega$-TA from $V$. fluvialis JS17 for instance possesses high activity to $\alpha$-methylbenzylamine but also catalyzes the transamination of $\beta$-amino-n-butyric acid to the corresponding keto acid (Shin and Kim 2002,). $\beta$ Alanine and $\beta$-phenylalanine do not serve as substrates Yun et al. (2004) reported an $\omega$-TA from Alcaligenes denitrificans $\mathrm{Y} 2 \mathrm{k}-2$ which converts various aliphatic $\beta$ amino acids and amines but exhibits no activity towards $\beta$-phenylalanine. An exception is the $\omega$-TA from Caulobacter crescentus which showed minor activity towards $\beta$-phenylalanine (Hwang et al. 2008,). However, the relative activity of the wild-type enzyme towards $\alpha$-methylbenzylamine was nearly 170 -fold higher, towards $\beta$ alanine and $\beta$-amino-n-butyric acid even 300-fold 56 . Shin and Kim (2002) constructed an active site model for the $\omega$-TA from $V$. fluvialis based on its substrate spectrum. The authors tested a wide variety of donor and acceptor substrates and postulate a two-binding site model consisting of two pockets, one large and one small. The small pocket appears to accommodate no side group larger than ethyl groups and exhibits a strong repulsion for acidic groups. The carboxyl group is therefore always placed in the large pocket which results in the other side group of the substrate to be placed in the small pocket. Thus, high activities can be observed for $\beta$-amino acids with small side groups, e.g. $\beta$-amino-nbutyric acid, but not for large side chains like the aromatic ring of $\beta$-phenylalanine. 1-Phenylethylamine, on the other hand, does not possess a carboxylic group. Thus, the aromatic side-chain can be placed into the large pocket. For the confirmation of this model, the crystal structure will have to be elucidated. Jang et al. recently reported the crystallization and preliminary $\mathrm{X}$ ray structure of the $\omega$-TA from $V$. fluvialis (Jang et al. 2010,). The crystal structure has not been released yet (Park and Jang 2010).

Only a small number of TAs with high activity towards aromatic $\beta$-amino acids have been described (s. Table 2) and only two sequences, from the TA of the soil bacterium Mesorhizobium sp. LUK (GenBank: ABL74379.1) (Kim et al. 2007) and from the $\omega$-TA Ml0107 from M. loti MAFF303099 (GenBank: NP_101976.1) (Kwon et al. 2010), have been elucidated and published to date. The TA from Mesorhizobium sp. LUK shows, as reported by the authors, the highest identity (53\%) and similarity (66\%) to a glutamate-1semialdehyde 2,1-aminomutase of Polaromonas sp. strain JS666. Taking into consideration sequences which were submitted to Genbank since the publication of this article, the comparison of this amino acid sequence using blastp gives a putative aminotransferase class III from Variovorax paradoxus S110 (Gene ID: :7970445) as the closest match with $52 \%$ identities and $69 \%$ similarity. Interestingly, of the other transaminases reported to act on $\beta$-phenylalanine, one belongs to the species $V$. paradoxus (Banerjee et al. 2005) and two to the genus Variovorax (Brucher et al. 2010,Mano et al. 2006). The preliminary X-ray structure of the TA from Mesorhizobium sp. LUK has been published recently (Kim 2011).

Wild-type $\omega$-TAs almost universally exhibit $(S)$-selectivity. Notable exceptions are the $\omega$-TA of Arthrobacter sp. KNK168 (Iwasaki et al. 2003,Iwasaki et al. 2006) and its homolog, the commercially available ATA-117 (Codexis Inc.) as well as the TA from Alcaligenes eutrophus (Banerjee et al. 2005,) 59. Svedendahl and coworkers (2010) could invert the enantioselectivity of an $(S)$ selective $\omega$-TA from Arthrobacter citreus by single point mutation for their model substrate 4-fluorophenylacetone. This change in enantioselectivity was substratedependent. Whether or not this approach proves to be useful for the inversion of enantioselectivity of other TAs, remains to be seen.

Protein design of TAs for a modified or expanded substrate spectrum

Both rational design and directed evolution have been employed with the aim to enhance the activity of TAs towards aryl- $\beta$-amino acids 25 . Hwang and coworkers (2004) reported the directed evolution of the $\omega$-TA from $V$. fluvialis by error-prone PCR in order to increase activity towards $\beta$-phenylalanine. The best mutant exhibited a threefold activity increase in the conversion of $\beta$-phenylalanine compared to the wildtype. However, the yield of the transamination of $\beta$-phenylalanine was below $5 \%$ in $20 \mathrm{~h}$. The same group later modified an $\omega$-TA from Caulobacter crescentus which exhibited high activities towards short, aliphatic $\beta$-amino acids by site-directed mutagenesis (Hwang et al. 2008). A 3D model was constructed by homology modeling using a dialkylglycine decarboxylase as a template. This led to a threefold increase in activity for $\beta$-phenylalanine. Compared to the over 100-fold higher activity towards short, aliphatic $\beta$-amino acids, this is still quite low.

\section{Screening strategies for microbial TAs acting on $\beta$-amino acids}

\section{Enrichment culture and in-silico screening}

The first directed screenings for microorganisms exhibiting TA activity towards $\beta$-amino acids were performed by enrichment culture using the desired $\beta$ amino acid as a major or the sole nitrogen source. Toyama et al. (Toyama et al. 1973) isolated the strain Pseudomonas sp. F-126 by enrichment culture from soil using a medium containing $\beta$-alanine. Further studies 
revealed it to possess an $\omega$-amino acid:pyruvate TA with high activity towards $\beta$-alanine and other $\omega$-amino acids (Yonaha et al. 1976). With a similar approach most of the currently known TAs with activity towards $\beta$-amino acids were discovered. As the sequence-function relationship among TAs is as of yet poorly understood, enrichment culture still constitutes the greatest source of new TAs active towards $\beta$-amino acids.

However, some attempts have been made to identify interesting TAs from the ever growing number of completely sequenced genomes. Kaulmann et al. (2007) used the sequence of the $\omega$-TA from $V$. fluvialis for the in silico screening of novel TAs. They cloned and purified a putative TA from Chromobacterium violaceum which showed a similar substrate spectrum as the one from $V$. fluvialis. In a similar approach the previously described TA from Caulobacter crescentus was identified using the sequence of an $\omega$-TA from Alcaligenes denitrificans as a template (Hwang et al. 2008,). The novel TA exhibited high activities towards short, aliphatic $\beta$-amino acids and aromatic amines. Recently, Kwon et al. (Kwon et al. 2010) established the cell-free expression of computationally predicted putative $\omega$-TAs, which circumvents cloning and expression procedures. As part of this study, the putative $\omega$-TA Ml0107 from M. loti MAFF303099 was identified based on its sequence homology with the previously described TAs from Caulobacter crescentus and V. fluvialis. $\omega$-TA Ml0107 exhibited activity to $\beta$-phenylalanine, 1 -aminoindane and benzylamine.

The sequences of the two TAs with high activity towards aromatic $\beta$-amino acids (TA from Mesorhizobium sp. LUK (Kim et al. 2007), $\omega$-TA Ml0107 from $M$. loti MAFF303099 (Kwon et al. 2010)) have, to the best of our knowledge, so far not been used for in-silico screening.

\section{Activity assays for high-throughput screening}

A major limiting step in the discovery, characterization, optimization and purification of new TAs lies in the determination of TA activity. This gave rise to the development of several high-throughput (HTP)-methods. Figure 3 gives an overview over HTP-assays which allow the screening for TA activity towards $\beta$-amino acids.

The first assay was realized by Hwang et al. (2004). It is based on the formation of a blue amino acid-copper complex by the $\alpha$-amino acid produced in the TA reaction and $\mathrm{CuSO}_{4} / \mathrm{MeOH}$ staining solution (see Figure $3 a)$. The assay was tested using a great variety of aliphatic and aromatic $\beta$-amino acids as amino donors with good accuracy. Furthermore, by using both enantiomers of an amino donor separately, information on the enantiopreference of the studied enzyme could be gained. A disadvantage of this method consists in the fact that the staining solution inhibits the enzyme, so that it can only be applied as an end-point measurement. Additionally, this method does not allow the use of cell extracts as free $\alpha$-amino acids disturb the reaction. Thus, enzyme purification is necessary. Therefore the application of this assay is rather limited. Coupling the determination of TA activity with driving the reaction to completion, Truppo et al. (2009) developed an elegant multi-enzymatic system for the HTP-screening and scale-up of TA catalyzed reactions (see Figure $3 \mathrm{~b}$ ). In this system, pyruvate which is generated through the TA reaction is reduced to L-lactate by a lactate dehydrogenase (LDH). Recycling of the LDH cofactor NADH by glucose dehydrogenase $(\mathrm{GDH})$ ultimately leads to the formation of gluconic acid and thus to a $\mathrm{pH}$ drop. The progression of the reaction can be measured by monitoring the change of absorbance of a $\mathrm{pH}$ indicator (phenol red). This system proved to be especially useful for rapid scale-up. While the system was only tested with ketones as substrate, theoretically $\beta$-keto acids could also be employed. Limits of the reaction are that only pyruvate dependent TAs can be tested, no information on the enantioselectivity or enantiopreference of the studied enzyme can be gained and that as it is a multi-enzymatic system, reaction conditions can only be altered marginally. Additionally, most $\beta$-keto acids are instable due to spontaneous decarboxylation. A potential solution to this crucial problem is discussed in the conclusion section. A simple assay for the screening of $\omega$-TAs has been developed by Schätzle et al. (2009). The assay is based on the transamination of the model substrate $\alpha$-methylbenzylamine to acetophenone (see Figure 3c). Acetophenone exhibits high absorbance around $245 \mathrm{~nm}$. While this assay does not directly screen for activity towards $\beta$-amino acids, $\alpha$-methylbenzylamine constitutes a good model substrate for $\omega$-TAs which also possess activity towards short-chain aliphatic $\beta$-amino acids. Advantages of this assay are its applicability to cell extracts, the possibility to determine the enantiopreference by using enantiopure $\alpha$-methylbenzylamine and its high sensitivity. The same group recently published another assay which allows the determination of amino donor specificity (see Figure 3d) (Schätzle et al. 2010,). The principle of the assay differs from all other presented methods as it measures the change of conductivity of the reaction mixture. The progression of the reaction results in a decrease of conductivity as charged compounds (a positively charged amine and a negatively charged keto acid) are converted to non-conducting products (a non-charged ketone and a zwitterionic amino acid). Advantages of this assay are the broad spectra of amino donors and amino acceptors which can be used and its high sensitivity. Yet the mode of analysis itself makes the simultaneous measurement of many samples cumbersome as 
(a)

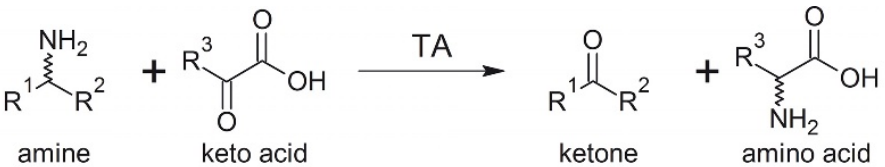

$$
\begin{aligned}
& \downarrow \mathrm{CuSO}_{4} / \mathrm{MeOH} \\
& \text { copper- amino acid complex } \\
& 595 \mathrm{~nm}
\end{aligned}
$$

(b)<smiles>N[C@@H](C[CH+]C(=O)c1ccccc1)C(=O)O</smiles><smiles>Cc1cccc(C(N)[C+]C(=O)O)c1</smiles>
acetophenone L-alanine 1-phenylethylamine

pyruvate gluconolactone $\rightarrow$ gluconic acid

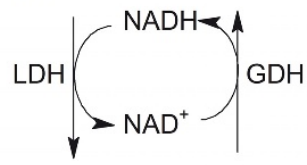

L-lactate glucose

(c)<smiles>[R]C([R])=O</smiles><smiles>[R]C([Z7])N([R])C</smiles>

1-phenylethylamine ketone acetophenone amine<smiles>C1CCCCC1</smiles>
$245 \mathrm{~nm}$

(d)

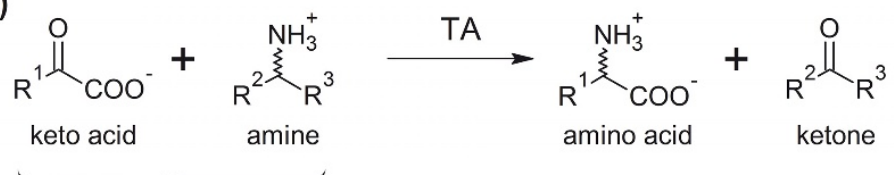

charged compounds

(e)

$$
\text { amine }
$$

Figure 3 Activity assays for the screening of novel transaminases (a) by formation of a blue copper complex with the produced $\alpha$ amino acid, (b) by withdrawal of the produced pyruvate in a multi-enzymatic one-pot reaction system which ultimately leads to a pH drop, (c) by direct measurement of the absorbance of acetophenone produced from the transamination of $\alpha$-methylbenzylamine, (d) by measuring the decrease in conductivity which results from the conversion of the two charged substrates to the uncharged/ zwitterionic products and (e) by oxidation of the produced alanine which ultimately leads to the oxidation of the dye pyrogallol red by $\mathrm{H}_{2} \mathrm{O}_{2}$ in a multi-enzymatic one-pot reaction system. Abbreviations: $\mathrm{LDH}=$ lactate dehydrogenase, $G D H=$ glucose dehydrogenase, $A A O=$ amino acid oxidase, HRP = horse radish peroxidase. 
each reaction tube or well would have to be equipped with an electrode. This conductivity assay should also work using a $\beta$-keto acid instead of an $\alpha$-keto acid, leading to the zwitterionic $\beta$-amino acid and an uncharged ketone. However, the potential spontaneous decarboxylation of the charged $\beta$-keto acid to an uncharged compound might lead to some conductivity decrease even without TA activity. Hopwood et al. (2011) recently described a multi-enzymatic reaction system employing an amino acid oxidase which converts the co-product of the transamination reaction, $\mathrm{D}$ - or L-alanine, to the corresponding imine (see Figure 3e). The hereby produced $\mathrm{H}_{2} \mathrm{O}_{2}$ oxidizes, catalyzed by horse radish peroxidase, the dye pyrogallol red. The reaction can be monitored by measuring the decrease in absorbance around $540 \mathrm{~nm}$. This method allows the use of many different amine donors as well as the determination of the enantiopreference of the transaminase. When using a $\beta$-amino acid instead of an amine, false positive results might occur if the amino acid oxidase (AAO) also oxidizes the educt and not only the coproduct. However, to our knowledge such AAO activity towards $\beta$-amino acids has never been reported. Further drawbacks include that free amino acids distort the results, which makes enzyme purification necessary and that as it is a multi-enzymatic reaction system, reaction conditions can only be changed marginally.

\section{Conclusions and future areas of research}

TAs possess a great potential for the enzymatic synthesis of enantiopure $\beta$-amino acids as these enzymes offer the possibility to gain a $100 \%$ yield in contrast to the conventional kinetic resolutions using other biocatalysts (see introduction). Transaminases are commonly used tools in the synthesis of various chemicals and pharmaceuticals. Thus production and purification of these enzymes in bulk quantities is well-established, and so is immobilization. Additionally, several process parameters for biotechnological applications are well investigated for both kinetic resolutions and asymmetric syntheses, e.g. the usage of different (co-)solvents and variation of $\mathrm{pH}$ and PLP concentration as well as different strategies of product removal (Koszelewski et al. 2008,). Of special importance are the thoroughly tried and tested methods to shift the equilibrium to the product side by removal of the coproduct (kinetic resolutions) or degradation of the coproduct/recycling of the amino donor by different enzymes in asymmetric synthesis (Koszelewski et al. 2010).

All these benefits for technical applications are not established with aminomutases and only in part with hydantoinases (as described above), so TAs appear as the most promising candidates among the potential biocatalysts for a $100 \%$ yield synthesis of $\beta$-amino acids.
A key step in fulfilling this potential is the discovery of new TAs with a broader substrate spectrum and different enantioselectivity. This will be greatly facilitated by the HTP-activity assays described in this article, which allow for time and cost efficient screening, characterization and enzyme optimization. As has been discussed, transaminases which act on aliphatic $\beta$-amino acids are abundant, while only a small number of transaminases which act on aromatic $\beta$-amino acids have been described. The application of protein engineering to enhance the activity of TAs towards aromatic $\beta$-amino acids has been only moderately successful. The crystal structure of the transaminase of Mesorhizobium sp. LUK will lead to a more targeted approach in protein engineering.

Little attention so far has been paid to the preparation of the thermodynamically instable $\beta$-keto substrate. A possible route is the enzymatic hydrolysis of the corresponding $\beta$-keto-ester. Although such a route has already been described (Banerjee et al. 2005, Kim et al. 2007,) further optimization will be necessary for the development of efficient processes as the reported yields are quite low $(\sim 20 \%)$. This might be due to the loss of the intermediary $\beta$-keto acid via decarboxylation to acetophenone (which is not discussed in Kim et al. 2007).

This instability of the potential substrates indeed appears as the bottleneck in $\beta$-amino acid synthesis via transaminases. A more elegant solution could be obtained by changing the sequence in this coupled enzyme reaction: If the TA accepts the stable $\beta$-keto ester (1) the intermediary synthesis of the $\beta$-keto acid can be circumvented and (2) the adjacent application of an enantioselective lipase to subsequently cleave the intermediary chiral $\beta$-amino acid ester would further enhance the ee value. As the authors assume this can not happen in the reported reaction due to a mandatory anchoring of the substrate's carboxylic group by one of the two binding pockets around the PLP-lysine Schiff base (the external aldimine intermediate) which is certainly not possible with the esterified substrate (Kim et al. 2007).

However, advances in protein design and substrate modeling might help to overcome this problem, as for example the excavation of the small pocket of the commonly used transaminase ATA-117 allowed the (R)selective amination of prositagliptin ketone to the antidiabetic compound sitagliptin (Savile et al. 2010) which was not successful before using a variety of unmodified TAs due to sterical hindrance.

Not least, the potential of TAs for the asymmetric synthesis of $\beta$-amino acids can be assumed to be even much higher, as most of the numerous commercially available TAs have never been tested with $\beta$-amino acids or $\beta$-keto acids as substrates (the latter due to 
their instability mentioned above). So the conclusive key step will be a modification of the HTP-assays described to allow a fast and comprehensive screening for $\beta$-TA activity.

\section{Acknowledgements}

We would like to thank the "Bundesministerium für Bildung und Forschung" (BMBF) for the financial support of this work within the joint project "BioSysPro": New enzymes and processes for biobased products via the integration of biotechnological and chemical methods.

\section{Competing interests}

The authors declare that they have no competing interests.

Received: 20 January 2012 Accepted: 31 January 2012

Published: 31 January 2012

\section{References}

Aguilar MI, Purcell AW, Devi R, Lew R, Rossjohn J, Smith Al, Perlmutter P (2007) Beta-amino acid-containing hybrid peptides - new opportunities in peptidomimetics. Org Biomol Chem 5:2884-2890. doi:10.1039/b708507a.

Bach RD, Canepa C (1996) Electronic factors influencing the decarboxylation of beta-keto acids. A model enzyme study. J Org Chem 61:6346-6353

Banerjee A, Chase M, Clayton R, Landis B (2005) Methods for the stereoselective synthesis and enantiomeric enrichment of beta-amino acids. WO/2005/ 005633

Braunstein AE, Kritzmann MG (1937) Formation and breakdown of amino-acids by inter-molecular transfer of the amino group. Nature 140:503-504

Brucher B, Syldatk C, Rudat J (2010) Microbial conversion of beta-phenylalanine using new transaminase. Chem Ing Tech 82:155-160. doi:10.1002/ cite.200900110

Burnett G, Walsh C, Yonaha K, Toyama S, Soda K (1979) Stereospecificity of enzymatic transamination of gamma-aminobutyrate. J Chem Soc, Chem Commun 826-828

Chen DZ, Wang Z, Zhang YJ, Sun ZY, Zhu Q (2008) An amine:hydroxyacetone aminotransferase from Moraxella lacunata WZ34 for alaninol synthesis. Bioprocess Biosyst Eng 31:283-289. doi:10.1007/s00449-007-0158-4.

Christen P, Metzler DE (1985) Transaminases. John Wiley \& Sons, New York

Cooper AJL, Meister A (1989) An appreciation of Braunstein, Alexander E. The discovery and scope of enzymatic transamination. Biochimie 71:387-404

Cox BM, Bilsborrow JB, Walker KD (2009) Enhanced conversion of racemic aarylalanines to (R)- $\beta$-arylalanines by coupled racemase/aminomutase catalysis. J Org Chem 74:6953-6959. doi:10.1021/jo9009563.

Eliot AC, Kirsch JF (2004) Pyridoxal phosphate enzymes: Mechanistic, structural, and evolutionary considerations. Annu Rev Biochem 73:383-415. doi:10.1146/ annurev.biochem.73.011303.074021.

Engel U, Syldatk C, Rudat J (2011) Stereoselective hydrolysis of aryl-substituted dihydropyrimidines by hydantoinases. Appl Microbiol Biotechnol (in press). doi: 10.1007/s00253-011-3691-7

Finn RD, Mistry J, Tate J, Coggill P, Heger A, Pollington JE, Gavin OL, Gunasekaran P, Ceric G, Forslund K, Holm L, Sonnhammer ELL, Eddy SR, Bateman A (2010) The Pfam protein families database. Nucleic Acids Res 38: D211-D222. doi:10.1093/nar/gkp985.

Frackenpohl J, Arvidsson PI, Schreiber JV, Seebach D (2001) The outstanding biological stability of beta- and gamma-peptides toward proteolytic enzymes: an in vitro investigation with fifteen peptidases. ChemBioChem 2:445-455. doi:10.1002/1439-7633(20010601)2:63.0.CO;2-R.

Frey PA, Hegeman AD (2007) Enzymatic reaction mechanisms. Oxford University Press, New York

Gopi HN, Ravindra G, Pal PP, Pattanaik P, Balaram H, Balaram P (2003) Proteolytic stability of beta-peptide bonds probed using quenched fluorescent substrates incorporating a hemoglobin cleavage site. FEBS Lett 535:175-178. doi:10.1016/50014-5793(02)03885-1.

Grishin NV, Phillips MA, Goldsmith EJ (1995) Modeling of the spatial structure of eukaryotic ornithine decarboxylases. Protein Sci 4:1291-1304. doi:10.1002/ pro. 5560040705.

Hayashi H, Mizuguchi H, Miyahara I, Islam MM, Ikushiro H, Nakajima Y, Hirotsu K, Kagamiyama H (2003) Strain and catalysis in aspartate aminotransferase.
Biochimica Et Biophysica Acta-Proteins and Proteomics 1647:103-109. doi:10.1016/S1570-9639(03)00068-2.

Hintermann T, Seebach D (1997) The biological stability of beta-peptides: No interactions between alpha- and beta-peptidic structures. Chimia 51:244-247

Höhne M, Bornscheuer UT (2009) Biocatalytic routes to optically active amines. ChemCatChem 1:42-51. doi:10.1002/cctc.200900110.

Hook DF, Gessier F, Noti C, Kast P, Seebach D (2004) Probing the proteolytic stability of beta-peptides containing alpha-fluoro- and alpha-hydroxy-betaamino acids. ChemBioChem 5:691-706. doi:10.1002/cbic.200300827.

Hopwood J, Truppo MD, Turner NJ, Lloyd RC (2011) A fast and sensitive assay for measuring the activity and enantioselectivity of transaminases. Chem Commun 47:773-775. doi:10.1039/c0cc02919j.

Horne WS, Johnson LM, Ketas TJ, Klasse PJ, Lu M, Moore JP, Gellman SH (2009) Structural and biological mimicry of protein surface recognition by alpha/ beta-peptide foldamers. PNAS 106:14751-14756. doi:10.1073/ pnas.0902663106

Hu J, Xue YC, Xie MY, Zhang R, Otani T, Minami Y, Yamada Y, Marunaka T (1988) A new macromolecular antitumor antibiotic, C-1027. 1. Discovery, taxonomy of producing organism, fermentation and biological activity. J Antibiot 41:1575-1579

Hwang B-Y, Kim B-G (2004) High-throughput screening method for the identification of active and enantioselective omega-transaminases. Enzyme Microb Technol 34:429-436. doi:10.1016/j.enzmictec.2003.11.019.

Hwang B-Y, Cho B-K, Yun H, Koteshwar K, Kim B-G (2005) Revisit of aminotransferase in the genomic era and its application to biocatalysis. J Mol Catal B: Enzym 37:47-55. doi:10.1016/j.molcatb.2005.09.004.

Hwang B-Y, Ko S-H, Park H-Y, Seo J-H, Lee B-S, Kim B-G (2008) Identification of omega-aminotransferase from Caulobacter crescentus and site-directed mutagenesis to broaden substrate specificity. J Microbiol Biotechnol 18:48-54

Iverson BL (1997) Betas are brought into the fold. Nature 385:113-115. doi:10.1038/385113a0.

Iwasaki A, Yamada Y, Ikenaka Y, Hasegawa J (2003) Microbial synthesis of (R)- and (S)-3,4-dimethoxyamphetamines through stereoselective transamination. Biotechnol Lett 25:1843-1846. doi:10.1023/A:1026229610628.

Iwasaki A, Yamada Y, Kizaki N, Ikenaka Y, Hasegawa J (2006) Microbial synthesis of chiral amines by (R)-specific transamination with Arthrobacter sp. KNK168. Appl Microbiol Biotechnol 69:499-505. doi:10.1007/s00253-005-0002-1.

Jang T-H, Kim B, Park O-K, Bae J-Y, Kim B-G, Yun H, Park H-H (2010) Crystallization and preliminary $X$-ray crystallographic studies of omega-transaminase from Vibrio fluvialis JS17. Acta Crystallogr, Sect F- Struct Biol Cryst Commun 66:923-925. doi:10.1107/S1744309110021573.

Kaulmann U, Smithies K, Smith MEB, Hailes HC, Ward JM (2007) Substrate spectrum of omega-transaminase from Chromobacterium violaceum DSM30191 and its potential for biocatalysis. Enzyme Microb Technol 41:628-637. doi:10.1016/j.enzmictec.2007.05.011.

Kim J, Kyung D, Yun H, Cho B-K, Seo J-H, Cha M, Kim B-G (2007) Cloning and characterization of a novel beta-transaminase from Mesorhizobium sp. strain LUK: a new biocatalyst for the synthesis of enantiomerically pure beta-amino acids. Appl Environ Microbiol 73:1772-1782

Kim B, Park OK, Bae JY, Jang TH, Yoon JH, Do KH, Kim B-G, Yun H, Park HH (2011) Crystallization and preliminary X-ray crystallographic studies of $\beta$ transaminase from Mesorhizobium sp. strain LUK. Acta Crystallogr Sect F Struct Biol Cryst Commun 67:231-233. doi:10.1107/S1744309110050876.

Koert U (1997) Beta-peptides: novel secondary structures take shape. Angew Chem, Int Ed 36:1836-1837. doi:10.1002/anie.199718361.

Koszelewski D, Lavandera I, Clay D, Rozzell D, Kroutil W (2008) Asymmetric synthesis of optically pure pharmalogically amines employing $\omega$ transaminases. Adv Synth Catal 350:2761-2766. doi:10.1002/adsc.200800496.

Koszelewski D, Tauber K, Faber K, Kroutil W (2010) Omega-transaminases for the synthesis of non-racemic alpha-chiral primary amines. Trends Biotechnol 28:324-332. doi:10.1016/j.tibtech.2010.03.003.

Kwon YC, Lee KH, Kim HC, Han K, Seo JH, Kim BG, Kim DM (2010) Cloningindependent expression and analysis of omega-transaminases by use of a cell-free protein synthesis system. Appl Environ Microbiol 76:6295-6298. doi:10.1128/AEM.00029-10.

Liu M, Sibi MP (2002) Recent advances in the stereoselective synthesis of $\beta$ amino acids. Tetrahedron 58(40):7991-8035. doi:10.1016/50040-4020(02) 00991-2.

Mano J, Ogawa J, Shimizu S (2006) Microbial production of optically active betaphenylalanine through stereoselective degradation of racemic beta- 
phenylalanine. Biosci Biotechnol, Biochem 70:1941-1946. doi:10.1271/ bbb.60099.

Montero A, Beierle JM, Olsen CA, Ghadiri MR (2009) Design, synthesis, biological evaluation, and structural characterization of potent histone deacetylase inhibitors based on cyclic alpha/beta-tetrapeptide architectures. J Am Chem Soc 131:3033-3041. doi:10.1021/ja809508f.

Moyle Needham D (1930) A quantitative study of succinic acid in muscle III. Glutamic and aspartic acids as precursors. Biochem J 24:208-227

Nurbo J, Peterson SD, Dahl G, Danielson UH, Karlen A, Sandstrom A (2008) Betaamino acid substitutions and structure-based CoMFA modeling of hepatitis C virus NS3 protease inhibitors. Bioorg Med Chem 16:5590-5605. doi:10.1016/j. bmc.2008.04.005.

Park HH, Jang T (2010) Crystal structure of omega-transferase from Vibrio fluvialis JS17. Protein Data Bank (PDB). http://www.pdb.org/pdb/results/results.do? tabtoshow=Unreleased\&qrid=3DF8060E. Accessed 27 June 2011

Percudani R, Peracchi A (2009) The B6 database: a tool for the description and classification of vitamin B6-dependent enzymatic activities and of the corresponding protein families. BMC Bioinf 10:273-280. doi:10.1186/14712105-10-273.

Rehdorf J, Mihovilovic MD, Bornscheuer UT (2010) Exploiting the regioselectivity of Baeyer-Villiger monooxygenases for the formation of $\beta$-amino acids and $\beta$-amino alcohols. Angewandte Chemie International 49(26):4506-4508. doi:10.1002/anie.201000511. doi:10.1002/anie.201000511.

Savile CK, Janey JM, Mundorff EC, Moore JC, Tam S, Jarvis WR, Colbeck JC, Krebber A, Fleitz FJ, Brands J, Devine PN, Huisman GW, Hughes GJ (2010) Biocatalytic asymmetric synthesis of chiral amines from ketones applied to sitagliptin manufacture. Science 239:305-309

Schätzle S, Höhne M, Redestad E, Robins K, Bornscheuer UT (2009) Rapid and sensitive kinetic assay for characterization of omega-transaminases. Anal Chem 81:8244-8248. doi:10.1021/ac901640q.

Schätzle S, Hohne M, Robins K, Bornscheuer UT (2010) Conductometric method for the rapid characterization of the substrate specificity of aminetransaminases. Anal Chem 82:2082-2086. doi:10.1021/ac9028483.

Schneider G, Kack H, Lindqvist Y (2000) The manifold of vitamin B6-dependent enzymes. Structure 8:R1-R6. doi:10.1016/S0969-2126(00)00085-X.

Seebach D, Overhand M, Kühnle FNM, Martinoni B, Oberer L, Hommel U, Widmer H (1996) Beta-peptides: Synthesis by Arndt-Eistert homologation with concomitant peptide coupling. Structure determination by NMR and CD spectroscopy and by X-ray crystallography. Helical secondary structure of a beta-hexapeptide in solution and its stability towards pepsin. Helv Chim Acta 79:913-941

Seebach D, Matthews JL (1997) Beta-peptides: A surprise at every turn. Chem Commun 21:2015-2022

Seebach D, Gademann K, Schreiber JV, Matthews JL, Hintermann T, Jaun B, Oberer L, Hommel U, Widmer H (1997) 'Mixed' beta-peptides: a unique helical secondary structure in solution. Helv Chim Acta 80:2033-2038. doi:10.1002/hlca.19970800703.

Seebach D, Gardiner J (2008) Beta-peptidic peptidomimetics. Acc Chem Res 41:1366-1375. doi:10.1021/ar700263g.

Shin J-S, Kim B-G (1999) Asymmetric synthesis of chiral amines with omegatransaminase. Biotechnol Bioeng 65:206-211. doi:10.1002/(SICI)1097-0290 (19991020)65:23.0.CO;2-9.

Shin J-S, Kim B-G (2002) Exploring the active site of amine:pyruvate aminotransferase on the basis of the substrate structure-reactivity relationship: how the enzyme controls substrate specificity and stereoselectivity. J Org Chem 67:2848-2853. doi:10.1021/jo016115i.

Shin J-S, Yun H, Jang J-W, Park I, Kim B-G (2003) Purification, characterization, and molecular cloning of a novel amine:pyruvate transaminase from Vibrio fluvialis JS17. Appl Microbiol Biotechnol 61:463-471

Steer DL, Lew RA, Perlmutter P, Smith Al, Aguilar MI (2002) Beta-amino acids: versatile peptidomimetics. Curr Med Chem 9:811-822. doi:10.2174/ 0929867024606759.

Svedendahl M, Branneby C, Lindberg L, Berglund P (2010) Reversed enantiopreference of an omega-transaminase by a single-point mutation. ChemCatChem 2:976-980. doi:10.1002/cctc.201000107.

Tasnádi G, Forró E, Fülöp F (2008) An efficient new enzymatic method for the preparation of $\beta$-aryl- $\beta$-amino acid enantiomers. Tetrahedron: Asymmetry 19(17):2072-2077. doi:10.1016/j.tetasy.2008.08.009.

Taylor PP, Pantaleone DP, Senkpeil RF, Fotheringham IG (1998) Novel biosynthetic approaches to the production of unnatural amino acids using transaminases. Trends Biotechnol 16:412-418. doi:10.1016/S0167-7799(98) 01240-2.

Toyama S, Miyasato K, Yasuda M, Soda K (1973) Occurence of taurine-pyruvate aminotransferase in bacterial extract. Agric Biol Chem 37:2939-2941. doi:10.1271/bbb1961.37.2939.

Truppo MD, Rozzell JD, Moore JC, Turner NJ (2009) Rapid screening and scale-up of transaminase catalysed reactions. Org Biomol Chem 7:395-398. doi:10.1039/b817730a.

Wani MC, Taylor HL, Wall ME, Coggon P, McPhail AT (1971) Plant antitumor agents. 6. Isolation and structure of taxol, a novel antileukemic and antitumor agent from Taxus brevifolia. J Am Chem Soc 93:2325-2327

Ward J, Wohlgemuth R (2010) High-yield biocatalytic amination reactions in organic synthesis. Curr Org Chem 14:1914-1927. doi:10.2174/ 138527210792927546.

Weiner B, Szymanski W, Janssen DB, Minnaard AJ, Feringa BL (2010) Recent advances in the catalytic asymmetric synthesis of $\beta$-amino acids. Chem Soc Rev 39(5):1656-1691. doi:10.1039/b919599h.

Wu B, Szymanski W, Heberling MM, Feringa BL, Janssen DB (2010) Aminomutases: mechanistic diversity, biotechnological applications and future perspectives. Trends Biotechnol 29:352-362

Wu B, Szymanski W, de Wildeman S, Poelarends GJ, Feringa BL, Janssen DB (2010) Efficient tandem biocatalytic process for the kinetic resolution of aromatic $\beta$-amino acids. Adv Synth Catal 352:1409-1412. doi:10.1002/ adsc. 201000035

Yonaha K, Toyama S, Yasuda M, Soda K (1976) Purification and crystallization of bacterial omega-amino acid-pyruvate aminotransferase. FEBS Lett 71:21-24. doi:10.1016/0014-5793(76)80889-7.

Yonaha K, Toyama S, Yasuda M, Soda K (1977) Properties of crystalline omegaamino acid - pyruvate aminotransferase of Pseudomonas sp. F-126. Agric Biol Chem 41:1701-1706. doi:10.1271/bbb1961.41.1701.

Yonaha K, Suzuki K, Minei H, Toyama S (1983) Distribution of omega-amino acid: pyruvate transaminase and aminobutyrate: alpha-ketoglutarate transaminase in microorganisms. Agric Biol Chem 47:2257-2265. doi:10.1271/ bbb1961.47.2257.

Yun H, Lim S, Cho B-K, Kim B-G (2004) Omega-amino acid:pyruvate transaminase from Alcaligenes denitrificans Y2k-2: a new catalyst for kinetic resolution of beta-amino acids and amines. Appl Environ Microbiol 70:2529-2534. doi:10.1128/AEM.70.4.2529-2534.2004.

doi:10.1186/2191-0855-2-11

Cite this article as: Rudat et al:: Transaminases for the synthesis of enantiopure beta-amino acids. AMB Express 2012 2:11.

\section{Submit your manuscript to a SpringerOpen ${ }^{\circ}$ journal and benefit from:}

- Convenient online submission

- Rigorous peer review

- Immediate publication on acceptance

- Open access: articles freely available online

- High visibility within the field

- Retaining the copyright to your article

Submit your next manuscript at $\gg$ springeropen.com 